\title{
Disorders of spelling
}

\section{KINSBOURNE AND ELIZABETH K. WARRINGTON}

\author{
From the National Hospital, Queen Square, London, and the Department of Neurology, \\ United Oxford Hospitals
}

The writing process may be regarded as in the first instance compounded of spelling (requiring correct choice and sequence of letters) and of script (demanding correct formation of letters). Impairment in each activity may be studied separately and their respective contributions towards a clinically apparent writing disorder assessed. Spelling, with which we are here concerned; can be studied in isolation from script if performed orally.

A spelling disorder may be a feature of central or expressive aphasia. Ih the writing of a series of aphasic patients, Weisenburg and McBride (1935) found errors of choice of letter to be prominent.

Gerstmann (1924) reported a disorder of writing in association with finger agnosia. Many subsequent case reports of the Gerstmann syndrome present examples of mis-spelling, among which errors of order of letters are prominent.

Clinical observations thus suggest that patients with finger agnosia tend to make spelling errors involving letter order, while aphasics characteristically make errors of letter choice. The present study was designed to test this possibility in a formal manner.

\section{CLINICAL STUDY}

The methods of testing were the following:

FINGER AGNOSIA Tests of finger differentiation and order (Kinsbourne and Warrington, 1962) were used. These test for the same defect as Gerstmann's (1924) tests for finger agnosia but do not require the patients to know the names of the fingers.

APHASIA. Clinical tests of comprehension of speech and expression were used. These included naming common objects, explaining common sayings, carrying out single and double instructions, and learning a simple sentence.

SPELLING DISORDER Spelling was tested orally, using Schonell's graded word spelling lists (Schonell and Schonell, 1950). The words were read out beginning with the easiest. The patient's first attempt at spelling the word was recorded. No time limit was imposed, but efforts at self-correction were not taken into account. As the procedure differed from that customary when the test is given to children, no attempt was made to score it in terms of spelling age. Instead, an overall error score waș obtained.

INTELLECTUAL STATUS All patients except those in control group IV (extracranial lesions) were tested on the Wechsler adult intelligence scale. Further clinical tests for the presence of selective defects referable to cerebraies hemisphere dysfunction were employed. These included tests of reading, writing, drawing, and memory.

SELECTION OF PATIENTS Four groups of patients wereo included in this study. These were selected as follows:

Group I: Patients with finger agnosia This group waso drawn from patients referred to the Psychology Depart-in ment between February 1962 and April 1963 on suspicion of cerebral cortical disease. Twelve patients fell into tîisiv category, for which failure on the tests of finger differentiation and order was the sole and sufficient criterion

Group II: Patients with aphasia This was a group of patients with a clinically obvious speech impairment $8 \mathrm{f}_{\mathrm{c}}$ aphasic type (apart from spelling) similarly referred between February 1962 and April 1963. The only ad- $\bar{D}$ ditional criterion for selection was a pass on the tests for finger agnosia. Aphasic patients who failed the finger teis were included in group $I$ (cases $3,7,9,10,11$ ). The size ${ }^{\circ}{ }^{+}$ the original group of aphasics tested was sixteen.

Group III: Patients with right hemisphere lesions This was a group of right-handed patients with evidence of $\overline{\bar{O}}$ right hemisphere lesions. These were the sole criteria foro selection of the original group of 15 patients.

Group IV: Patients with extracranial lesions This group consisted of patients none of whom had evidence $\overline{\bar{O}}$ of disease affecting the brain. The original group con- $\overline{3}$ tained 13 patients.

The patients were tested on oral spelling as describedo above. The test contained 100 words. Patients who spelled fewer than 20 words correctly were excluded from the analysis, as were those who made fewer than 10 errors, and thus provided insufficient data. Table I gives the size

\section{TABLE I}

SELECTION OF GROUPS OF PATIENTS

\begin{tabular}{llllll}
$\begin{array}{l}\text { Patient } \\
\text { Group }\end{array}$ & \begin{tabular}{l} 
No. of Patients \\
\cline { 2 - 6 }
\end{tabular} & $\begin{array}{l}\text { Originally } \\
\text { Tested }\end{array}$ & $\begin{array}{l}\text { With Fewer than } \\
\text { 20 Words Correct }\end{array}$ & $\begin{array}{l}\text { With Fewer than } \\
\text { IO Words Incorrect }\end{array}$ & $\begin{array}{l}\text { In Finat Group } \\
\text { 20 }\end{array}$ \\
\hline I & 12 & 1 & 0 & 11 \\
II & 16 & 3 & 0 & 13 \\
III & 15 & 0 & 2 & 13 & 0 \\
IV & 13 & 0 & 3 & 10 & $\omega$
\end{tabular}


of the original groups of patients, together with the number of patients excluded, and the final size of the groups used in the analysis that followed. Tables IIa and IIb present psychological findings on the patients finally included in group I (finger agnosia) and group II (aphasia but no finger agnosia) respectively.

\section{METHOD OF ANALYSIS OF SPELLING ERRORS}

The spelling of patients with cerebral cortical lesions may be wildly incorrect. Multiple errors may occur within one word, and at times such errors might be classifiable in more than one way. It was therefore decided to let each mis-spelled word appear only once in the analysis and to establish a 'hierarchy' of spelling errors to determine the category of error where more than one type of error was present.

The particular method of analysis described below was suggested by clinical observations of extraneous letter errors in aphasic spelling, and order errors in association with finger agnosia. Omission errors were also often noted in the presence of finger agnosia. Vowel substitutions and reduplications were not uncommon in normal people, and perhaps often reflect educational shortcomings.

TYPES OF ERROR Types of error were classified as follows:

1 Extraneous letters Any word contaminated by an extraneous letter (defined as one that does not in fact occur anywhere in it) was classified under the heading 'extraneous letters'. Irrespective of the presence of any other errors in the word, it was then excluded from further analysis.

2 Letter order errors Of the residue, every word in which there occurred (a) an interchange in position of two letters or letter groups or (b) a letter out of turn (unless it represented an immediate repetition of the letter, error type 5, or was limited to vowels, error type 4) was classified as containing an order error and excluded from further analysis.

3 Letter omissions of the residue, every word in which one or more letters were omitted was classified as containing an 'omission' error and excluded from further analysis.

4 Vowel substitution Of the residue, each word in which there was substituted for a vowel another one that also occurred elsewhere in the word was classified as a 'vowel substitution'.

5 Reduplications This left only the erroneous reduplications of a letter, which were classified under this heading.

The first 10 mis-spellings produced by each patient were subjected to analysis. Further errors (on more difficult words) were not included, as when a person is tested on words well outside his range his efforts become wilder and less specific. Each patient, therefore, was represented in the calculations by 10 mis-spelled words, irrespective of the overall severity of the disability or the presence of multiple errors within one word.

\section{RESULTS}

THE SPELling ANALYSIS The overall spelling score (number of words correct out of 100) obtained on the Schonell word lists for each patient in group I and II is given in Table II. The mean spelling scores were as follows: Group I 66.6 , group II 54.7 , group III $71 \cdot 0$, and group IV $79 \cdot 4$. The scores obtained by the four groups do not directly represent their relative spelling efficiency as spelling achievement was equated to the extent of demanding a score of between 20 and 90 for inclusion in the study. A number of patients had, therefore, to be excluded from each of the four groups because they made too few errors (in the case of the control groups III and IV, Table I). Even after selection on this basis the two control groups obtained a higher mean score than either the aphasia or the finger agnosia group, but only in the case of the aphasia group does the difference reach significance. If the initial selection were taken into account the differences would be greater.

ANALYSIS OF SPELLING ERRORS Ten mis-spelled words from each patient were classified as described above. The incidence of each type of error, for each group of patients, was estimated as a percentage of the total errors made. The percentage of each type of error for each group is given in Table III.

Differences in the incidence of the types of spelling error among the four groups of patients were tested for significance by means of the $\chi^{2}$ test.

The proportionate incidence of omission errors and vowel substitution errors showed no significant difference between the four groups $\left(\chi^{2}=2 \cdot 3\right.$ and 6.4 respectively). Reduplication errors were too few to permit analysis. The distribution of order errors in the four groups was significantly different at the $1 \%$ level of probability $\left(\chi^{2}=20 \cdot 6\right)$. This showed that order errors do not occur equally frequently in these four groups of patients. Extraneous letter errors also do not occur with equal frequency in the four groups of patients (significant difference at the $0.1 \%$ of probability, $\chi^{2}=23 \cdot 5$ ).

Groups III and IV, the two control groups, were compared with respect to the incidence of extraneous letter errors and order errors when $\chi^{2}$ was 0.36 and 0.01 respectively, which is not significant at the $5 \%$ level of probability. Therefore, for the remaining analyses groups III and IV were combined and regarded as a single control group.

The aphasic group and the control group were compared with respect to the incidence of extraneous letter errors and order errors. It was found that significantly more extraneous letter errors were made by the aphasic group $\left(\chi^{2}=22 \cdot 2\right.$, significant at the $1 \%$ level), as well as significantly fewer order errors $\left(\chi^{2}=7 \cdot 4\right.$, significant at the $5 \%$ level $)$.

The finger agnosia and control groups were com- 
TABLE IIa

PSYCHOLOGICAL FINDINGS IN PATIENTS IN GROUP I

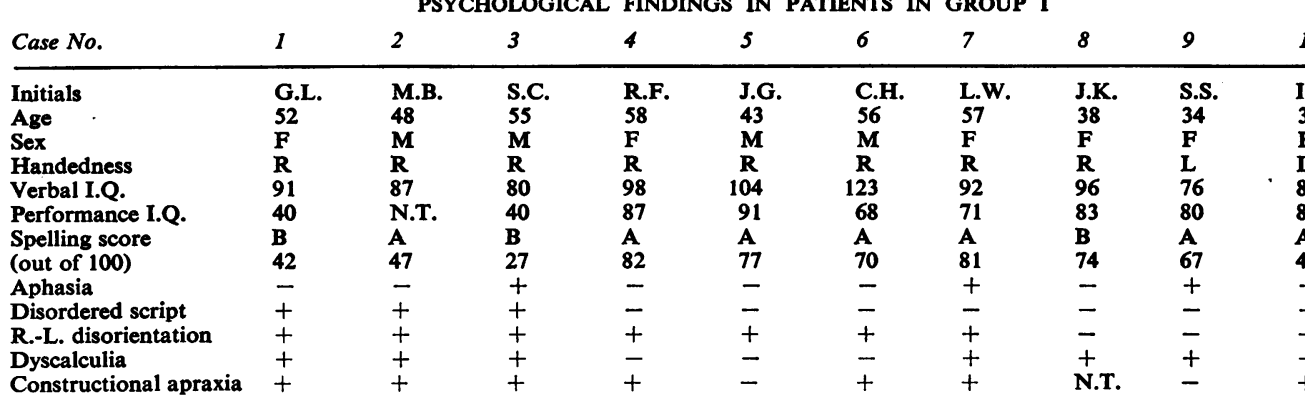

TABLE IIb

PSYCHOLOGICAL FINDINGS IN PATIENTS IN GROUP II

\begin{tabular}{|c|c|c|c|c|c|c|c|c|c|}
\hline Case No. & 1 & 2 & 3 & 4 & 5 & 6 & 7 & 8 & 9 \\
\hline $\begin{array}{l}\text { Initials } \\
\text { Age } \\
\text { Sex } \\
\text { Handedness } \\
\text { Verbal I.Q. } \\
\text { Performance I.Q. } \\
\text { Progressive matrices }\end{array}$ & $\begin{array}{l}\text { D.B. } \\
59 \\
\text { M } \\
\text { R } \\
93 \\
123 \\
40 / 60\end{array}$ & $\begin{array}{l}\text { S.R. } \\
71 \\
M \\
\text { R } \\
69 \\
82\end{array}$ & $\begin{array}{l}\text { A.H. } \\
54 \\
M \\
\text { R } \\
68 \\
96\end{array}$ & $\begin{array}{l}\text { A.K. } \\
59 \\
\text { M } \\
\text { R } \\
87 \\
101\end{array}$ & $\begin{array}{l}\mathbf{R} . \mathbf{N} \text {. } \\
\mathbf{5 8} \\
\mathbf{M} \\
\mathbf{R} \\
96 \\
84\end{array}$ & $\begin{array}{l}\text { O.B. } \\
55 \\
\text { M } \\
\text { R } \\
\text { N.T. } \\
\text { N.T. } \\
\text { 32/60 }\end{array}$ & $\begin{array}{l}\text { L.M. } \\
59 \\
\text { M } \\
\text { R } \\
95 \\
97 \\
28 / 60\end{array}$ & $\begin{array}{c}\text { H.J. } \\
64 \\
M \\
\text { R } \\
122 \\
\text { N.T. } \\
41 / 60\end{array}$ & $\begin{array}{l}\mathbf{J . H} . \\
\mathbf{3 8} \\
\mathbf{M} \\
\mathbf{R} \\
\mathbf{6 7} \\
\mathbf{8 0}\end{array}$ \\
\hline $\begin{array}{l}\text { Disordered script } \\
\text { Spelling score }\end{array}$ & - & - & N.T. ${ }^{1}$ & N.T. ${ }^{1}$ & - & + & - & - & - \\
\hline (out of 100) & 78 & 25 & 32 & 73 & 64 & 53 & 89 & 83 & 21 \\
\hline R.-L. disorientation & - & - & - & - & - & - & + & - & - \\
\hline $\begin{array}{l}\text { Dyscalculia } \\
\text { Constructional }\end{array}$ & - & + & - & 一 & - & - & + & - & + \\
\hline apraxia & - & - & N.T. ${ }^{1}$ & N.T. ${ }^{1}$ & + & - & - & - & - \\
\hline
\end{tabular}

1 Not tested for on account of right hemiplegia.

TABLE III

DISTRIBUTION OF SPELLING ERROR TYPES IN THE FOUR GROUPS OF PATIENTS

\begin{tabular}{|c|c|c|c|c|c|}
\hline Errors & $\begin{array}{l}\text { Extraneous } \\
\text { Letter }\end{array}$ & Order & $\begin{array}{l}\text { Vowel } \\
\text { Substitution }\end{array}$ & Omission & Reduplicatien \\
\hline $\begin{array}{l}\text { Group I: Finger agnosia } \\
\quad(\mathrm{N}=11)\end{array}$ & $\begin{array}{l}19 \\
(17 \%)\end{array}$ & $\begin{array}{l}35 \\
(32 \%)\end{array}$ & $\begin{array}{l}11 \\
(10 \%)\end{array}$ & $\begin{array}{l}44 \\
(40 \%)\end{array}$ & $\begin{array}{l}1 \\
(1 \%)\end{array}$ \\
\hline $\begin{array}{l}\text { Group II: Aphasics } \\
(\mathbf{N}=13)\end{array}$ & $\begin{array}{l}63 \\
(49 \%)\end{array}$ & $\stackrel{9}{(7 \%)}$ & $\begin{array}{l}14 \\
(11 \%)\end{array}$ & $\begin{array}{l}38 \\
(29 \%)\end{array}$ & $\begin{array}{l}7 \\
(4 \%)\end{array}$ \\
\hline $\begin{array}{l}\text { Group III: Right. hemisphere } \\
(\mathrm{N}=13)\end{array}$ & $\begin{array}{l}33 \\
(25 \%)\end{array}$ & $\begin{array}{l}22 \\
(17 \%)\end{array}$ & $\begin{array}{l}27 \\
(21 \%)\end{array}$ & $\begin{array}{l}43 \\
(33 \%)\end{array}$ & $\begin{array}{l}5 \\
(4 \%)\end{array}$ \\
\hline $\begin{array}{l}\text { Group IV: Extracranial } \\
(\mathbf{N}=10)\end{array}$ & $\begin{array}{l}22 \\
(22 \%)\end{array}$ & $\begin{array}{l}17 \\
(17 \%)\end{array}$ & $\begin{array}{l}15 \\
(15 \%)\end{array}$ & $\begin{array}{l}38 \\
(38 \%)\end{array}$ & $\begin{array}{l}8 \\
(8 \%)\end{array}$ \\
\hline $\begin{array}{l}\text { Combined control (III + IV) } \\
(\mathbf{N}=23)\end{array}$ & $\begin{array}{l}55 \\
(24 \%)\end{array}$ & $\begin{array}{l}39 \\
(17 \%)\end{array}$ & $\begin{array}{l}42 \\
(18 \%)\end{array}$ & $\begin{array}{l}81 \\
(35 \%)\end{array}$ & $\begin{array}{l}13 \\
(6 \%)\end{array}$ \\
\hline
\end{tabular}

pared with respect to the incidence of extraneous and order errors. Significantly more order errors were made by the finger agnosia group $\left(\chi^{2}=9 \cdot 7\right.$, significant at the $5 \%$ level). The difference in incidence of extraneous letter errors between the two groups did not reach significance $\left(\chi^{2}=1.9\right)$. These results are summarized in Table IV.

Only order errors and extraneous letter errors occurred with significantly different frequencies in the four groups. This inequality of distribution was the result of aphasic patients making more extraneous letter errors and fewer order errors and finger agnosia patients making more order errors. As regards the incidence of omission errors and vowel substitution errors, the finger agnosia and the aphasia groups didô not differ significantly from the control group.

\section{DISCUSSION}

The finger agnosia and the aphasia group each showed a distinctive pattern of incidence of the various types of spelling error. These patients occupy 
TABLE IV

CORRELATIONS BETWEEN GROUPS OF PATIENTS AND TYPES OF ERROR

\begin{tabular}{|c|c|c|c|c|}
\hline & Extraneous & Order & Omission & Vowel Substitution \\
\hline The four groups of patients & $\begin{array}{l}\chi^{2}=23.5 \\
\text { Significant } \\
(P=0.001)\end{array}$ & $\begin{array}{l}\chi^{2}=20.6 \\
\text { Significant } \\
(P=0.001)\end{array}$ & $\begin{array}{l}x^{2}=2.3 \\
\text { Not significant } \\
(P<0.05)\end{array}$ & $\begin{array}{l}x^{2}=6.4 \\
\text { Not significant } \\
(P>0.05)\end{array}$ \\
\hline Group III/group IV & $\begin{array}{l}x^{2}=0.36 \\
\text { Not significant } \\
(P>0.05)\end{array}$ & $\begin{array}{l}\chi^{2}=0.01 \\
\text { Not significant } \\
(P>0.05)\end{array}$ & & \\
\hline $\begin{array}{l}\text { Group I/control group } \\
\text { (finger agnosia) }\end{array}$ & $\begin{array}{l}\chi^{2}=1.9 \\
\text { Not significant } \\
(P>0.05)\end{array}$ & $\begin{array}{l}\chi^{2}=9.7 \\
\text { Significant } \\
(P=0.01)\end{array}$ & & \\
\hline $\begin{array}{l}\text { Group II/control group } \\
\text { (aphasia) }\end{array}$ & $\begin{array}{l}\chi^{2}=22 \cdot 2 \\
\text { Significant } \\
(P=0.001)\end{array}$ & $\begin{array}{l}x^{2}=7.4 \\
\text { Significant } \\
(P=0.01)\end{array}$ & & \\
\hline
\end{tabular}

the opposite ends of a spectrum, with the two control groups in an intermediate position. Each group made errors of every kind; the difference lay in the relative proportion.

In brief, the aphasic group yielded a high proportion of extraneous letter errors, and the finger agnosia group a high proportion of letter order errors. Errors of omission and vowel substitutions did not discriminate between the groups. Reduplications were too few to permit conclusions to be drawn (Table III).

The results show that at least two factors may limit oral spelling ability in the presence of cerebral pathology. While in one group of cases the spelling disability reflects a more general language disorder, in the other group it is related to deficits not limited to the verbal sphere.

Gerstmann's (1924) patient with finger agnosia wrote in a 'practically illegible scribble'. Subsequent more detailed analyses of comparable cases have been reported as showing, among other things, errors of letter order (Herrmann and Pötzl, 1926; Lange, 1930), extending also to oral spelling (Wagner 1932). In the present study this type of error, in oral spelling, was prominent in a group of patients with finger agnosia. In view of the double dissociation between the finger agnosia and the aphasia groups, in respect of order errors and extraneous letters, the spelling disability of the finger agnosia group cannot be due to aphasia. The high proportion of order errors suggests a difficulty in evoking the letters in correct sequence. As Critchley (1953) remarked in another context, 'Some disorders of spelling can be regarded less as grammatical errors than as a spatiotemporal disability.' Such a disability might extend beyond spelling so as to embarrass, in an analogous manner, the recall of non-verbal information.

The classifying of stimuli (both verbal and nonverbal) in terms of their relative positions in space and time was thought by Lashley (1951) to represent a distinctive mode of cerebral functioning. Finger agnosia, which has been shown to be associated with order errors in spelling is based on an underlying difficulty in classifying the fingers in terms of their relative positions (Kinsbourne and Warrington, 1962). Finger agnosia and order errors in spelling may thus be manifestations of an underlying disorder of cerebral functioning of the type suggested by Lashley.

Belief in the integrity of the Gerstmann syndrome has been challenged by a study with negative outcome (Benton, 1961), which, however, failed to take account of the distinctive features of its elements. In the present study, for example, it was the type of the spelling errors, rather than their mere occurrence, which distinguished the finger agnosia group. If a total error score only had been obtained, the distinction from the aphasic group would have been missed. It may be that further attempts at establishing the coherence of the syndrome regarded as the expression of a disorder of spatio-temporal sequencing will meet with more success.

The presence of an oral spelling disability of 'order error type' in association with finger agnosia is not indicative of a more general language disorder. To regard it as such would lead to a spuriously high estimate of the incidence of aphasia in association with finger agnosia (Heimburger, DeMyer, and Reitan, 1964).

The patients with finger agnosia (group I) included five who had a coincident aphasia (Table I). Nevertheless, as a group they produced a pattern of spelling error of types differing widely from that of the aphasics (group II). An alternative approach would have been to exclude from the analysis all cases with both aphasia and finger agnosia, but it was thought that to use failure on the finger tests as the sole criterion for inclusion in group I would be the more objective method.

Attention was confined to the first 10 mis-spelled words produced by each patient when tested on the graded word list. Had care not been taken in each 
case to use for analysis words only just beyond the patient's spelling capacity, the correlations might well have been obscured by non-specific errors on words with which the patient had perhaps never been really familiar. The method used showed also that the pattern of errors may point to a disability not revealed by the overall score for spelling errors. Patients 4 and 7 in group I and 7 and 8 in group II produced tell-tale patterns of error in spite of a total score well within the limits set by the control population. Presumably their pre-morbid spelling ability was still higher, but this cannot usually be accurately determined in retrospect and in a mild case only the error pattern may reveal a spelling disability.

The relative proportions of the error types produced by the patients with right hemisphere lesions (group III) approximated closely to those found with control group IV. If any variety of right (minor) hemisphere lesion gives rise to a specific impairment of oral spelling, this was not brought out by the present study.

The features of spelling performance which have been discussed relate to groups of patients. They are statistical findings, and cannot be directly applied to the individual case. There may be a considerable difference not only in total error score but also in patterns of error between individual members of a group, as well as overlapping between groups.

Of the 11 patients in group I, selected on account of the presence of finger agnosia, nine had right-left disorientation, four disorders of script, and eight dyscalculia. In group II (13 patients with aphasia but without finger agnosia) there were two instances of right-left disorientation, two (out of nine cases able to be tested) of disordered script, and six of dyscalculia. The incidence of the classical Gerstmann elements is seen to be higher in the finger agnosia group. Whether the instances of right-left disorientation and dyscalculia in group II, in the absence of finger agnosia, are, in fact, strictly comparable to those that occur in its presence (group I), or, as with oral spelling errors in the two groups, are referable in each instance to a different type of underlying disability, is not yet known.

\section{SUMMARY}

Oral spelling ability was tested by means of a standard $\bar{z}$ spelling test in four groups of patients. It was found $\stackrel{\mathbb{D}}{\subseteq}$ that aphasic patients and patients with finger agnosia each showed a distinctive pattern of spelling error when compared with control groups consisting of patients with right hemisphere and extracranialon lesions respectively. Aphasic mis-spellings included aô high proportion of extraneous letters. Patients with finger agnosia produced a high proportion of errors $\vec{z}$ relating to letter order. The control groups took up intermediate positions in these respects and did not? differ significantly from one another.

It was concluded that patients with aphasia and을 with finger agnosia mis-spell in different ways and for $\frac{\bar{p}}{\bar{D}}$ different reasons. The association of aphasic speech ${ }_{\Omega}^{\Phi}$ and extraneous letter errors in spelling seems to reflect the underlying disorder of language functions, while the association between finger agnosia and. order errors in spelling appears to reflect an under $-\vec{\omega}$ lying more general difficulty in processing informa- $-\mathrm{S}$ tion (both verbal and non-verbal) in terms of spatiotemporal sequence.

We are indebted to the physicians and surgeons of National Hospital, Queen Square, and of the Department of Neurology, the United Oxford Hospitals, for perms sion to study patients under their care. We wish foo $^{\circ}$ acknowledge the help of Miss Merle James in collecting the data.

\section{REFERENCES}

Benton, A. L. (1961). J. Neurol. Neurosurg. Psychiat., 24, 176. Critchley, M. (1953). The Parietal Lobes. Arnold, London.

Gerstmann, J. (1924). Wien. klin. Wschr., 37, 1010.

Heimburger, R. F., Neurosurg. Psychiat., 27, 52.

Herrmann, G., and Pötzl, O. (1926). Uber die Agraphie und ihre lokaldiagnostischen Beziehungen [Abh. Neurol. Psychiat Psychol. No. 35], Mschr. Psychiat. Neurol., suppl., 35.

Kinsbourne, M., and Warrington, E. K. (1962). Brain, 85, 461.

Lange, J. (1930). Mschr. Psychiat. Neurol., 76, 129.

Lashley, K. (1951). In Cerebral Mechanisms in Behavior, edited by L. A. Jeffress, p. 112. Wiley, New York.

Schonell, S. J., and Schonell, F. E. (1950). Diagnostic and Attain ment Testing. Oliver and Boyd, Edinburgh and London.

Wagner, W. (1932). Mschr. Psychiat. Neurol., 84, 281.

Weisenburg, T. H., and McBride, K. E. (1935). Commonwealth Press, New York. 